\title{
LAS ORDENACIONES SACERDOTALES EN EL ARZOBISPADO DE MÉXICO EN TIEMPOS DE LA INSURGENCIA, 1810-1821
}

\author{
THE PRIESTLY ORDINATIONS IN THE \\ ARCHBISHOPRIC OF MEXICO \\ DURING THE INSURGENCY, 1810-1821
}

\author{
Luis Fernando Vivero Domínguez \\ UNAM \\ viveroacademia@gmail.com
}

\begin{abstract}
The objective of this article is to analyze the tendencies of priestly ordination of secular clergy of the archdiocese of Mexico during the War of Independence in New Spain (1810-1821), through a book of registration of priestly orders. Its study becomes relevant because it is the most important diocese of the Spanish empire in America and because it is part of a politically turbulent period, where the clergy was an active subject and a focal point for the ecclesiastical authority.
\end{abstract}

Keywords: clergy, insurgency, priestly orders, archbishops.

\section{Resumen}

El objetivo de este artículo es analizar las tendencias de ordenación sacerdotal de clérigos seculares del arzobispado de México durante el periodo de la Guerra de Independencia en Nueva España (1810-1821) a través de un libro de matrículas de órdenes sacerdotales. Su estudio toma relevancia por tratarse de la diócesis más importante del imperio español en América y por enmarcarse en un periodo políticamente convulso, donde el clero fue un sujeto activo y un centro de atención para la autoridad eclesiástica.

Palabras clave: clero, insurgencia, órdenes sacerdotales, arzobispos.

1 El presente texto es derivado de una investigación más amplia que está actualmente en curso, inscrita en el Programa de Maestría en Historia de la Universidad Nacional Autónoma de México, donde estudio la evolución y tendencias ocupacionales de la población clerical en el arzobispado de México durante la segunda mitad del siglo XVIII. Agradezco los pertinentes comentarios de los dictaminadores a este artículo. 


\section{Introducción: \\ los clérigos del arzobispado de México en una coyuntura política a fines de la época colonial}

iFelices siglos en que la Iglesia tenía hombres puros y santos qué elegir! En los nuestros es

fuerza mitigar este rigor y escoger los menos malos; pero el sacerdocio, su espíritu, sus deberes y santidad, los mismos son ahora que antes. (LIZANA y BEAUMONT, 1803).

La ordenación de sacerdotes en las Indias fue una tarea constante entre las múltiples funciones de la Iglesia hispanoamericana durante los siglos virreinales. En el caso novohispano, luego de la creación de la diócesis de México y la fundación de la Real Universidad hacia mediados del siglo XVI, el clero diocesano comenzó un proceso de fortalecimiento que llegaría a su punto máximo en la centuria borbónica. La formación de nuevos clérigos era necesaria, pues sin este ejército de ministros el episcopado mexicano no habría adquirido la relevancia que tuvo ni hubiese cumplido cabalmente con sus tareas, tales como la administración de sacramentos, la dirección de las parroquias, la enseñanza de la doctrina y la expansión de la fe, funciones que legitimaban no sólo la presencia eclesiástica sino la del mismo aparato español en sus dominios americanos.

Hacia la primera mitad del siglo XVIII, las dimensiones numéricas de la clerecía alcanzaron una cifra inédita; su crecimiento no era un asunto menor, por lo que también la Corona española puso especial cuidado en regular su número (Aguirre Salvador, 2012). Aunque en Nueva España no hubo razones aparentes para que Madrid dudara de la deslealtad clerical, la experiencia acontecida tras la llegada de los Borbón al trono, donde una facción del clero apoyó a la causa austríaca, contribuyó a tratar con más mesura, atención y cautela el papel ejercido por la Iglesia dentro de la administración española (Farris, 1995); por ejemplo, lo que competía al número de clérigos, su número, disciplina e influencia en la vida social.
No resulta descabellada esta idea si tomamos en cuenta la predilección que tuvo la Corona en elegir mitrados peninsulares y capitulares leales a los intereses españoles, acto que desencadenó, en el caso novohispano, importantes críticas por parte del clero criollo que pretendía escalar a posiciones cada vez más altas al interior de la jerarquía eclesiástica (Lynch, 2001).

El protagonismo y el riesgo ejercidos por el clero no eran para menos. En el caso peruano, por ejemplo, Lynch (2001) sostuvo que después de la rebelión de Túpac Amaru, en 1780, las autoridades tuvieron especial desconfianza en los clérigos que administraban las tierras altas del Perú por tener la responsabilidad de ser agentes de cambio a favor de los intereses regios entre la población sublevada.

La Corona española sí temía una posible insubordinación de su clero y, según Farris (1995), esto había desencadenado el proyecto para desaparecer la inmunidad eclesiástica en los dominios españoles, y no sólo eso, también la puesta en marcha de diferentes políticas de reforma implementadas con mayor fuerza durante el reinado de Carlos III que pretendieron disminuir el radio de influencia del clero, particularmente de los curas que estaban al frente de las parroquias y en una relación más estrecha y fuerte con la población (Taylor, 1995).

En la Nueva España, la más clara oportunidad de probar la lealtad de la clerecía se presentó hasta los inicios de la insurgencia, en 1810. El clero parroquial del Bajío novohispano había comenzado el movimiento armado que a lo largo de la década se extendió por otras regiones del virreinato hasta desembocar en la separación política con España.

Si en las décadas precedentes a la insurrección el número excesivo de clérigos puso en duda la seguridad de los territorios hispanos, resulta conveniente estudiar cómo se comportaron durante el periodo de la insurgencia las ordenaciones sacerdotales, es decir, la formación de nuevos ministros en el arzobispado de México. La selección de este periodo no fue casual, pues desde los inicios 
de la lucha armada los sacerdotes se convirtieron en participantes activos de la guerra, vistos por los mitrados algunas veces como enemigos rebeldes y otras más como aliados capaces de detener a los insurgentes.

Más allá de estas consideraciones, la relevancia que ejerció el clero en el conflicto no fue minúscula, pues su cercanía con la población, su presencia en los pueblos y su participación activa o neutral en el conflicto podían inclinar la balanza hacia el bando insurgente que poco convenía a los intereses de la Corona.

Para exponer mi argumento he organizado este escrito en tres apartados consecutivos. El primero está dedicado a discutir qué tan significativos fueron los beneficios que otorgaba el estado eclesiástico -toda vez que se implementaron políticas reformistas a la Iglesia a finales del siglo XVIII- y si, aun con esto, el sacerdocio continuaba siendo un medio de subsistencia para la población novohispana.

Esto no sólo permitirá explicar las tendencias de ordenación sacerdotal, sino que también resulta útil para entender hasta qué grado las reformas constituyeron una razón para la participación del clero en la insurgencia.

Ligado a lo anterior, en el segundo apartado expongo un balance general del discurso que los arzobispos de México construyeron en torno a la figura de los curas novohispanos al tiempo que se gestaba la guerra civil, con el propósito de entender la postura sobre su clero y si ésta tuvo influencia o no en una apertura o limitación de los mitrados al momento de conferir órdenes sacras.

Finalmente, en el tercer segmento presentaré las tendencias de ordenación sacerdotal con los datos obtenidos del análisis de las matrículas de órdenes, así como las lecturas que al respecto pueden realizarse. Considero que atendiendo ambas posturas, las de las políticas de los mitrados y las aspiraciones de los clérigos, es posible elaborar una imagen más completa de las tendencias de ordenación en el periodo estudiado.

\section{Después de las reformas al clero: ¿aspiraciones frustradas para ingresar al estado eclesiástico?}

Los motivos por los cuales un individuo ingresaba al clero eran diversos, desde la presión familiar por la búsqueda de una estabilidad económica, las pretensiones de contar con un ingreso monetario seguro, la vocación por el ministerio sacerdotal (la cual muchas veces disfrazaba las verdaderas intenciones del aspirante) o simplemente porque correspondía con el estatus aristocrático de quien deseaba ordenarse. Más allá de estas razones, lo cierto es que el estado eclesiástico ofrecía importantes beneficios para quien ingresaba a él. ${ }^{2}$

Las reformas que la Corona española intentó aplicar al clero para disminuir su poder en sus virreinatos pretendieron reducir también aquellos beneficios. Éste no es el espacio para profundizar en el impacto de tales políticas; sin embargo, es necesario traerlas a colación para analizar si éstas frustraron las aspiraciones de quienes deseaban ordenarse. Es complejo responder esta pregunta y requerirá estudios más particulares sobre los ordenandos, pero considero que otros elementos podrían darnos luz sobre este aspecto.

En su multicitado libro sobre los párrocos del México borbónico, William Taylor (1999: 671) afirmó que los curas que participaron durante la insurgencia "no fueron principalmente jóvenes radicales que actuaran como si hubieran estado oprimidos por el alto clero o convencidos por las ideas liberales [...]". Esto significa que, en términos generales, es difícil establecer una correlación entre la aplicación de las reformas de fines del siglo XVIII con la beligerancia de los sacerdotes en el bando insurgente en la segunda década del siglo XIX. De hecho, en los años recientes, varios trabajos han sugerido matizar y diversificar las formas en que el clero participó en la lucha armada (Van Young, 2006; Aguirre Salvador, 2010). Profundizaré un poco más al respecto.

2 Si el lector desea profundizar en estos temas puede consultar los textos de Lavallé (2005) e Irigoyen López (2016). 
La proporción de sacerdotes del arzobispado de México que participó en la lucha armada es menor de lo que se suponía; sólo $10 \%$ de los curas -que no es lo mismo que el total de clérigos del arzobispado- formó parte de las filas insurgentes (Ibarra, 2010: 28-29). Según Taylor (1999: 669), el número de curas de la mitra mexicana que participó en la rebelión iniciada por el cura de Dolores fue de 145, de los cuales 39 fueron supuestos partidarios de la causa insurgente, mientras que el resto fue partidario confirmado.

Si bien es cierto que a lo largo del siglo XVIII los párrocos se habían consolidado como figuras centrales de la vida de los pueblos novohispanos, las diferencias en torno a su desempeño e influencia entre unos y otros al frente de su grey eran abismales (Van Young, 2006). Muchos sacerdotes que ejercían la cura de almas se habían convertido en enemigos declarados en sus curatos, al grado de protagonizar severos conflictos con sus parroquianos que escalaron hasta la Real Audiencia (Taylor, 1999; Vivero Domínguez, 2019). En otras palabras, el poder de convocatoria que tuvieron los curas del México borbónico fue muy relativo antes y durante la insurgencia.

Quizás esas interpretaciones previas derivaron de la centralidad que ocupó la figura de Miguel Hidalgo en el discurso que ensalzaba la lucha por la independencia, quien, al igual que otros sacerdotes que participaron en la reyerta, formaba parte del clero parroquial rural, ese en el que la mitra centró su atención y sus principales críticas por su importante cercanía con la población. Es cierto que muchas actitudes y cualidades de Hidalgo que han permitido explicar su participación en la guerra civil son aplicables para importantes sectores de la clerecía novohispana que no se enlistó en el bando insurgente, gracias a lo cual se mitificó el papel del cura de Dolores, lo deshumanizaron $y$, con ello, al resto del clero de México.

Entender las diversas motivaciones que tuvieron los clérigos para intervenir en el conflicto armado es más difícil que conocer el número de eclesiásticos que participó en la insurgencia. No es el objetivo de este texto profundizar en ese aspecto, pero me parece pertinente insistir en esta reflexión porque las explicaciones son tan diversas que nos deben ayudar a considerar si la mitra tuvo temores en la insubordinación de su clero, y si esta situación influyó en el otorgamiento de órdenes sacerdotales durante la década de la insurgencia.

Aguirre Salvador (2016) ha referido que las principales reformas que afectaron al clero parroquial en el siglo XVIII tuvieron que ver con el sustento de los curatos, cuya aplicación coincidió con un empobrecimiento de la población india. En buena medida estos cambios perjudicaron principalmente a la feligresía, mientras que a los curas lo hicieron de manera indirecta. Como consecuencia de ello, lo que vemos en el arzobispado es la capacidad que tuvo la clerecía de adaptarse a las nuevas circunstancias y no convertirse en un grupo reaccionario.

Pero la medida impositiva y extractiva más importante fue la Consolidación de Vales Reales, llevada a cabo en Nueva España entre 1805 y 1809. Von Wobeser (2006) afirma que la única respuesta del clero ante esta disposición ocurrió en el obispado de Michoacán y se trata de una representación del cabildo eclesiástico de esa diócesis de la que, aunque no se conoce el nombre del autor, es posible que haya sido impulsada por Manuel Abad y Queipo.

Von Wobeser (2006) considera que la política de consolidación sí derivó en que clérigos que perdieron sus capellanías se enlistaran en las filas insurgentes o realistas, aunque no como una respuesta revanchista contra la Corona, sino como una manera de emplearse y obtener algunos medios de subsistencia. No obstante, a partir de lo que algunos autores han señalado, el clero rural del arzobispado era ya, en gran medida, pobre; y esa tendencia bien puede rastrearse al menos desde mediados del siglo XVIII (Vizuete Mendoza, 2004), a raíz de las crisis de subsistencia por las que atravesaba la Nueva España al avanzar la centuria (Van Young, 1992).

En el sur novohispano, la zona más activa durante la segunda y tercera etapas de la 
insurgencia, tras la muerte de los primeros caudillos, la causa insurgente parece haber tenido poca simpatía entre los clérigos. Por ejemplo, en las regiones de la Costa Chica, la Costa Grande y la sierra, en el actual estado de Guerrero, la respuesta del clero parroquial fue más bien contrainsurgente (Hernández Jaimes, 2017).

No debe entenderse que el clero del arzobispado de México haya sido pasivo ante las políticas reformistas y que con ello se pretenda invisibilizar su participación en la insurgencia. El mismo Aguirre Salvador ha planteado la necesidad de ser más flexibles al momento de categorizar a los clérigos como insurgentes, realistas o neutrales. La propuesta de este autor es que los curas del arzobispado respondieron de maneras muy diversas a la insurgencia con ambigüedades convenientes que se sujetaron a los bandos, intereses y necesidades que se disputaban en los diferentes curatos (Aguirre Salvador, 2011).

Otro elemento que no debe escapar a estas reflexiones es que la Iglesia mexicana centró su interés en los párrocos, mas no en la importante masa de población clerical que se distribuía entre las diferentes órdenes sacerdotales, ni en aquellos clérigos que no ejercían el ministerio espiritual ni la cura de almas. A sabiendas de que la consecución de un curato era solamente una de tantas opciones donde el clero se podía emplear, parece que las reformas a la Iglesia no sólo no promovieron el descontento entre los clérigos, sino que tampoco inhibieron sus pretensiones por ser ordenados. ${ }^{3}$

En conclusión, los aspirantes a ingresar al estado eclesiástico no modificaron su percepción sobre los beneficios que les otorgaba convertirse en clérigos, pese al interés de la Corona por disminuir el radio de influencia de los sacerdotes. Ésta sólo es una de las va-

3 La gama de empleos donde podían ocuparse los clérigos era amplia y dependía de varios factores: las influencias, la preparación, los contactos y hasta la creatividad del ordenado. Por eso, el estado eclesiástico era atractivo a pesar de que no existieran parroquias suficientes donde los sacerdotes se pudieran emplear. Sobre este asunto puede revisarse el texto de Aguirre Salvador (2009). riables que nos permiten explicar el comportamiento de las tendencias de ordenación; una segunda variable, no menos importante, es la percepción que los arzobispos tuvieron sobre su clero durante la insurgencia, asunto que analizaré a continuación.

\section{La mitra mexicana y el clero: entre pastores de rebaño y soldados de Dios}

El sacramento del orden sacerdotal era una facultad exclusiva de los obispos, que podían convocar a los aspirantes a ser ordenados, así como añadir o retirar requisitos para quienes deseaban ingresar al estado eclesiástico. Si bien es cierto que la evolución numérica del clero era cambiante según el interés y las posibilidades de la población por ordenarse, los mitrados también podían intervenir en que sus cifras aumentaran, se estancaran o decrecieran. El interés de este apartado es realizar un balance general sobre la posición de los arzobispos de México frente a sus sacerdotes durante los años de la insurgencia, con el propósito de advertir los alcances que sus percepciones pudieron tener en la ordenación de nuevos clérigos.

Cuando el arzobispo Francisco Xavier de Lizana y Beaumont tomó posesión de su nueva mitra, en febrero de 1803, no pasó mucho tiempo para que fuera consciente de las circunstancias políticas y sociales que imperaban al interior de su diócesis. Es posible que su amistad y cercanía con Antonio de Lorenzana -quien había gobernado el arzobispado de México entre 1767 y 1771, y para quien Lizana y Beaumont había fungido como auxiliar de la arquidiócesis de Toledo en 1795- haya sido una vía de muchas para informarse del contexto que privaba en las diócesis americanas, en especial la de México (Castillo Flores, 2018).

De manera muy temprana, Lizana y Beaumont comunicó al rey la necesidad de limitar el ascenso de criollos a puestos significativos, pues una de las aspiraciones de estos -según el propio arzobispo- era la separación política de la metrópoli. Para Castillo Flores (2018), esto explicaría por qué el 
mitrado trabajó en favor de la reforma de las costumbres a través de cartas pastorales, visitas a parroquias y la implementación de políticas encaminadas a la corrección del clero y su disciplina, así como a la instrucción de la doctrina cristiana entre la grey por medio de las conferencias morales y las congregaciones de oblatos.

Lizana y Beaumont estaba convencido de que existía una relación correspondiente entre el desempeño de su clero con el orden social prevaleciente, de allí que tener una clerecía que mostrara un ejercicio adecuado de sus funciones era necesario para asegurar la dependencia política de la Corona (Castillo Flores, 2018). Parecía que, desde su arribo, el prelado estaba empecinado en resolver importantes problemáticas que aquejaban a su clero, tan es así que sólo unos meses después de su llegada publicó una carta pastoral sobre la "grandeza del estado sacerdotal y sus obligaciones". En ella, el arzobispo exhortaba a los eclesiásticos a ejercer funciones y comportarse según la medida de su investidura religiosa (Lizana y Beaumont, 1803).

El arzobispo era consciente de que no todos los clérigos se ordenaban por una verdadera vocación; sin embargo, les pedía expiar sus culpas "por medio de las buenas obras: conozcan su error, den principio a una vida nueva, santa y fervorosa, amando el retiro, trabajando por la salvación de las almas y abrasándose del zelo [sic] de la gloria de Dios [...]" (Lizana y Beaumont, 1803: 13). En esta carta donde el mitrado extendió su postura sobre los diferentes vicios del clero mexicano, mantuvo un eje en común y fue pretender que su clerecía, poco a poco, regresara a sus tareas espirituales con el fin de dignificar el estado sacerdotal, que a lo largo de las décadas había abandonado. El arzobispo se cuestionaba: "¿Qué mutación tan extraña vemos en nuestros días? ¿Cómo el sacerdocio real, oro purísimo en otro tiempo, ha mudado su color bello en obscuro y feo?" (Lizana y Beaumont, 1803: 15). Evidentemente estas acciones no eran más que la consecución de las políticas que sus antecesores habían implementado para la corrección de la disciplina del clero.

Desde los sucesos políticos de 1808 en España, en la metrópoli comenzó a gestarse el discurso de que se libraba una especie de guerra santa contra los invasores franceses, donde se debatían el bien -atribuido a la Monarquía católica- y el mal, representado por las fuerzas napoléonicas (Escrig Rosa, 2021). En la Nueva España previa a la insurgencia, la autoridad eclesiástica hizo suyo también este discurso, que replicó una vez iniciada la lucha contrainsurgente (Escrig Rosa, 2021).

Según José Escrig Rosa (2021), el clero español -en especial la alta jerarquía- promovió mensajes de carácter patriótico donde se vincularon los sentimientos religiosos y bélicos, al grado de vulgarizar términos teológicos. Es por eso que desde Lizana y Beaumont se advierte una transición al emitir sus puntos de vista sobre su clero, pues si primero se quejaba de que los criollos paulatinamente iban apropiándose de puestos clave y significativos en la clerecía, una vez estallada la insurgencia convocaría a la unidad de su Iglesia, no importando la calidad a la que se perteneciese. Aunque, claro, para un objetivo político: la salvación de España.

El proyecto de Lizana y Beaumont para la corrección del clero se vio truncado por tres razones sustanciales, en primer lugar, por su nombramiento como virrey de Nueva España en 1808, máxime en una situación crítica como la crisis política por la que atravesaba la península; en segundo lugar, la insurgencia encabezada por Hidalgo en el obispado de Michoacán en 1810; y en tercero, su repentina muerte, acaecida en mayo de 1811 (Castillo Flores, 2018).

Tras el fallecimiento de Lizana y Beaumont, el cabildo de la catedral agudizó el cambio del discurso ya iniciado por el prelado desaparecido. Sin importar que esta nueva visión del clero fuera en contra de la percepción generalizada que durante las últimas décadas se había construido sobre la clerecía, el cabildo señaló en un exhorto que "las virtudes, doctrina, celo y fidelidad de los eclesiásticos del Arzobispado no han sido jamás precarias ni dependientes de sus 
prelados" (García, 1906: 113). Dicho exhorto, pronunciado apenas unas semanas después de fallecido el prelado, tenía por objetivo mantener a la clerecía unida a la causa monárquica.

Para granjearse al clero, particularmente a los párrocos del arzobispado, el cabildo no reparó en elogios. Es interesante ver cómo, dadas las circunstancias políticas del momento, el discurso fundado sobre la percepción de los sacerdotes se nutrió de tintes políticos antes que críticos -si es que antes hubo algo de crítica en las opiniones sobre el clero-. Los sacerdotes pasaron de ser un sector incompetente, con vicios, y aptitudes reprobables para convertirse en:

el clero mexicano, ilustre y escogido por su nacimiento, educado cristiana y liberalmente, instruido en una multitud de colegios florecientes, graduado por lo general en una Universidad famosa, ilustrado por su tacto y conversación en la Corte con las personas más finas y políticas, [y que] ha sido por sí mismo noble en sus pensamientos, generoso en sus acciones, esclarecido en sus letras, ejemplar en su conducta (García, 1906: 113).

Este juego de palabras pretendía que los clérigos se definieran, o estaban a favor o en contra de la insurrección. Se construía así un anatema en contra de Miguel Hidalgo, el cura de la parroquia de Dolores, a quien el cabildo de México responsabilizaba -junto con otros ministros- de atizar el fuego y haberlo "soplado, mantenido y propagado"; sin embargo, los capitulares alardeaban que en la jurisdicción arzobispal ningún párroco se había involucrado en la rebelión (García, 1906: 115).

"¿Acaso alguno de ustedes tendrá tal osadía -cuestionaba el cabildo a sus clérigos- como para revertir esta tendencia en el arzobispado?". Adivinando la temerosa respuesta y para vanagloria futura de la mitra, los capitulares enarbolaban su discurso afirmando que:

cuando las generaciones futuras lean con horror los crímenes enormes, los proyectos abo- minables, los incalculables males de que ha sido autor en la Nueva España, un solo párroco pérfido, ignorante y entregado a Satanás, verán con indecible placer al clero de México, especialmente a los párrocos todos, reprobando tan inicua revolución (García, 1906: 116).

A la par que el cabildo ensalzaba la figura de los curas, aprovechaba para advertir a los eclesiásticos que, si bien estos tenían la posibilidad de ser juzgados por sus propios tribunales, reiteraba que "Nuestras manos mismas bañadas en lágrimas, y acompañadas del más íntimo dolor de nuestro corazón deberán arrojar de nuestra sociedad a unos miserables que ya no podemos abrigar a la sombra de nuestra pacífica legislación [...]" (AHAM, caja 166, exp. 44: f. 4). ${ }^{4}$

En el vecino obispado de Michoacán la postura de la mitra fue más agresiva. En 1811, el obispo electo, Manuel Abad y Queipo, prohibió la ordenación de sacerdotes a título de capellanía o beneficio, pues consideraba que el elevado número de clérigos en la revuelta era resultado del aumento descuidado de los ordenados, que además no tenían los medios suficientes para subsistir (Brading, 1981). Desde luego que estas diferencias derivaban de que la insurrección había comenzado en la diócesis vallisoletana.

A Lizana y Beaumont lo sucedió en la mitra de México el entonces obispo de Antequera, Antonio Bergosa y Jordán, quien fungió como arzobispo electo desde 1811 hasta 1815, aunque pudo trasladarse hasta 1813 a su sede en la capital novohispana (Ibarra González y Quezada Lara, 2018). Desde su estancia como obispo de Antequera, el electo arzobispo de México, Bergosa y Jordán, asumía una actitud más reaccionaria a la insurrección que el cabildo metropolitano. Mientras los capitulares de México concebían a los párrocos como dirigentes de la resistencia a través del púlpito, Bergosa y Jordán veía a los curas como figuras aptas para encabezar la defensa belicosa del reino, a quienes aprobó que tomaran las armas siempre que dejaran encargado en buenas manos el pasto espiritual de sus curatos

4 Archivo Histórico del Arzobispado de México. 
(Ibarra, 2000). Según Bravo Rubio y Pérez Iturbe (2001), el discurso de este prelado carecía de un sustento bíblico, histórico o doctrinal.

Para finales de su gestión al frente de la mitra mexicana, en 1815, el arzobispo Bergosa y Jordán lamentaba que la mayoría de su ejército de clérigos seculares no hubiese seguido el ejemplo y los llamamientos del arzobispado a cuidar los intereses de la Corona y de la Iglesia, a quienes reprendió: "seguramente si todos los confesores y predicadores hubiesen velado, predicado y clamado en todas partes sobre lo injusto de la insurrección, y sobre los extravíos y ruinas espantosas que trae consigo, ni estas hubieran sido tantas ni tan obstinada aquella" (AHAM, caja 166, exp. 44: f. 4).

Más adelante, en su misma carta pastoral, el arzobispo se apenaba -al igual que en su momento lo hizo Lizana y Beaumont- que el principal iniciador hubiera sido un pastor que motivó a sus ovejas a rebelarse:

Fue por nuestra desgracia un mal sacerdote el perverso autor y jefe de ella; siguiéronle otros semejantes de ambos cleros, secular y regular, [y] siguen otros con general asombro y mal ejemplo, de suerte que no sin algún fundamento se dice mantenerse la insurrección por el clero: ¿cómo pues podemos mirar esta infame nota con indiferencia? (AHAM, caja 166, exp. 44: ff. 4 y 5).

Pero no solamente eso, también reclamaba a sus clérigos -contra quienes elevó el tono de su discurso- que mostraban una actitud de indiferencia ante tales acontecimientos, a sabiendas de que aquellos, desde el púlpito, podían condenar también a los sacerdotes insurrectos:

Justo es quejarnos amargamente de semejantes sacerdotes, porque a semejanza de perros mudos que no quieren ladrar, y no podemos dejar de recordarles que tendrán que dar estrechísima cuenta a Dios por su falta de celo y caridad en retraer de la insurrección a los hombres, porque son responsables del pecado que no corrigen, y con su silencio se hacen acreedores de la execración y maldiciones del pueblo afligido con tantas calamidades (AHAM, caja 166, exp. 44: ff. 8 y 9).

Después de que Fernando VII recuperó el trono español, Bergosa y Jordán regresó a su antigua diócesis de Antequera sin ser confirmado como arzobispo de México (Hamnett, 2009). Un tanto decepcionado por la negación del monarca también habría aumentado su decepción de no haber encontrado en su clerecía un elemento activo contra la causa insurgente, o al menos eso se percibe en la carta pastoral antecedente.

En 1815, el monarca español decidió promover a la mitra mexicana a Pedro José de Fonte, antiguo provisor durante la gestión del arzobispo Lizana y Beaumont. El prelado tuvo una actitud mucho más prudente y menos radical que su antecesor en su afrenta a los movimientos insurreccionales, de manera que su gobierno arzobispal dio mayor atención a la pastoral cristiana mientras continuaban las luchas intestinas que transcurrieron desde la muerte de José María Morelos (1815) hasta la consecución de la independencia (1821).

Fonte realizó una visita pastoral entre 1819 y 1820 al norte del arzobispado, donde tuvo intenciones de preparar un clero indígena, pretendió la erección de una nueva diócesis segregada de su jurisdicción, proveyó 74 curatos que estaban vacantes con mayoría a curas americanos, tuvo interés en arreglar los seminarios diocesanos y colegios y reformó la congregación de oblatos para la mejora de su clero (Martínez Albesa, 2018).

En otras palabras, el arzobispo Fonte deseaba que su clerecía se abocara nuevamente a las tareas que había abandonado debido al contexto político imperante. A propósito de ello, en una carta pastoral fechada en octubre de 1816, el prelado arguyó: "amados Diocesanos, el habernos desviado de lo que Dios manda ha causado los males que padecemos, y volviendo a él hallaremos el remedio que necesitamos [...]" (Fonte, 1816: 7). 
Y en otra carta en la que incitaba a los curas al obedecimiento del monarca reinstalado en su trono, Fernando VII, el arzobispo Fonte enfatizó:

Tales han de ser las bases del sistema de nuestras operaciones, alejando de ellas todo espíritu de partido y siguiendo el único verdadero que nos prescribe la religión. De esta sola hemos de esperar el consuelo de nuestras angustias y el apoyo de nuestro celo en estos días amargos y turbulentos que Ilenan de aflicción a quien haya de cumplir con los deberes de pastor. En otro tiempo yo pudiera prometerme suavizar los vuestros con la promoción a otro destino de menos trabajo y mayores emolumentos [...] Más por eso no faltan otros estímulos más poderosos y menos falaces. Tales son los que nos propusimos o debimos proponer cuando entramos en el sacerdocio y nos encargamos del santuario (Fonte, 1815: 15).

Fonte, sin embargo, parecía tener confianza en sus clérigos, ${ }^{5}$ al igual que lo hizo su antecesor, el arzobispo Bergosa y Jordán. Aunque, desde luego, esa confianza tenía demasiada carga política. Una vez iniciada la insurrección, el arzobispado le otorgó el voto a sus sacerdotes, al tiempo que intentó granjearse al clero para que, a través de tácticas distintas, contribuyera a la prevalencia del statu quo que se encontraba en riesgo luego del estallido insurgente. Esto significaría que los mitrados no veían

5 En una carta enviada a la Junta Central que tomó el gobierno en la metrópoli, por el entonces provisor y futuro arzobispo, Pedro de Fonte, en 1809, señalaba que tras los sucesos de 1808 en la capital novohispana donde se pretendió la consecución de un gobierno alterno en tanto se restablecía la paz en España: "Algún regidor, clérigo, fraile, empleado subalterno y otros ociosos sin destino sintieron todo el peso de esta novedad y emplearon todos sus esfuerzos para causar otra. Pero ¿cuáles podían ser? Escribir papeles anónimos, poner pasquines, murmurar, quejarse, etcétera. Y ¿qué efecto podían producir? El que se ha visto: irritar por una parte a los europeos, que se han desazonado muchas veces por la lentitud y benignidad del actual gobierno contra sediciosas acciones; y recibirse con frialdad por otra, respecto que ni los indios ni las castas, ni los americanos exceptuados son capaces de dar un paso hacia el fin que se les proponía [la separación política de la metrópoli]" (Fonte, 1996: 297). algún riesgo en que los individuos buscaran su ordenación. ¿Las circunstancias políticas, económicas y sociales del momento fueron las que influyeron en las tendencias de ordenación sacerdotal? Veamos, pues, cómo se comportaron las ordenaciones durante este conflictivo periodo.

\section{Las tendencias de ordenación en el arzobispado de México durante una década conflictiva}

Ante el contexto político, social y discursivo referido en los apartados anteriores es momento de analizar las tendencias de ordenaciones sacerdotales en el arzobispado de México durante los años 1810 a 1821. La fuente principal para este estudio es el libro de matrículas de órdenes, que está fechado de 1790 a 1823, y que se conserva en el Archivo Histórico del Arzobispado de México. ${ }^{6}$ El libro presenta una división entre órdenes conferidas al clero regular y las otorgadas al clero secular, pero por ser los diocesanos el eje de este trabajo dejaré para otro momento el análisis de las ordenaciones de los frailes del arzobispado. Para una mayor comprensión de la información obtenida de la matrícula conviene hacer algunas precisiones conceptuales.

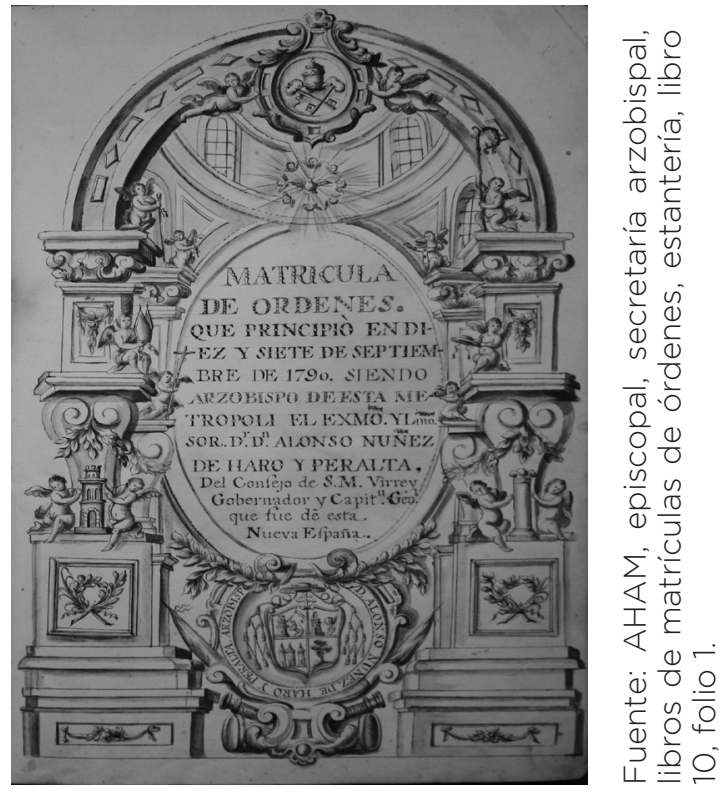

6 AHAM, episcopal, secretaría arzobispal, libros de matrículas de órdenes, estantería, libro 10. 
La ordenación sacerdotal era (y es) uno de los siete sacramentos de la Iglesia católica, y el obispo el único facultado para conferirla. En las sociedades del Antiguo Régimen, el camino para convertirse en sacerdotes constaba de una consecución de siete órdenes divididas en dos grupos: menores y mayores. El aspirante a clérigo comenzaba con la primera tonsura, seguido de las órdenes menores (ostiario, lector, exorcista y acólito), y continuando con el subdiaconado, diaconado y presbiterado, estas tres denominadas órdenes mayores. ${ }^{7}$

Las órdenes se podían obtener en su propia diócesis o en otra, siempre que el aspirante presentara su correspondiente dimisoria; es decir, un documento donde su prelado le concediese la posibilidad de ser ordenado en otra diócesis; sin embargo, para ello, estaba obligado el ordenando a "jurar domicilio" en la diócesis receptora. ${ }^{8}$ Debido a que un individuo podía recibir cinco órdenes diferentes (pues las órdenes menores se concebían, para fines prácticos, como una sola), el número de órdenes otorgadas por un prelado no coincidía numéricamente con el número de los ordenados. ${ }^{9}$

\footnotetext{
7 La primera tonsura era la primera de las órdenes que un aspirante recibía, la cual consistía en el corte del cabello hasta que quedase una especie de corona y significaba el inicio de la carrera para convertirse en presbítero; el tonsurado tenía entre sus tareas cantar los salmos, responsorios y lecciones. El ostiario tenía por función guardar las llaves del templo, tocar las campanas para llamar a la feligresía y cuidar el ingreso a la iglesia; el lector se encargaba de leer el Antiguo y Nuevo Testamento, así como cuidar el libro de las lecturas y las epístolas; el exorcista tenía por función la entrega del libro de los exorcismos; y el acólito se encargaba de entregar la vinajera vacía y el candelero con el cirio apagado. Ahora bien, con respecto a las órdenes mayores, el subdiácono era el clérigo que tenía facultad para leer o cantar la epístola; el diácono podía cantar el Evangelio, predicar y bautizar; y el presbítero estaba facultado para celebrar todos los sacramentos con excepción del orden sacerdotal (Murillo Velarde, 2004: 328-330)

8 Acerca de los requisitos de ordenación, el lector puede consultarlos en los decretos del Tercer Concilio Provincial Mexicano publicado por Pérez Puente et al. (2004).

9 Sobre este mismo aspecto debo advertir al lector que el correcto manejo de los conceptos será útil y necesario para entender la información que ofrecen las matrículas, y me refiero específicamente al cuidado de distinguir entre un clérigo, un cura y un presbítero. "Clérigo" era un término genérico con que se denominaba a cualquier individuo que fuese ordenado, indistintamente de la orden recibida; "cura" generalmente hacía referencia al titular de una parroquia; y por "presbítero" se entendía al clérigo que recibía la última de las órdenes mayores mediante la cual estaba posibilitado para concursar por la titularidad de una parroquia.
}

Las órdenes menores siempre eran conferidas en conjunto, es decir, no se otorgaba el grado de ostiario y después el de lector, sino las cuatro el mismo día. Éstas, junto con la primera tonsura que le antecedía podían ser conferidas en la misma celebración. Las menores y las mayores, así como el subdiaconado, diaconado y presbiterado no podían conferirse el mismo día. Cuando el aspirante a órdenes -por razones muy diversas- requería acelerar los tiempos para ser ordenado, solicitaba ante la Santa Sede una dispensa de intersticios.

Aquellos que aspiraran a ser ordenados podían hacerlo a través de diferentes vías llamadas en su conjunto "títulos". Quienes se ordenaban a título de lengua, por ejemplo, debían presentar un examen que aprobara el dominio de un idioma nativo; aquellos que se ordenaban a título de capellanía debían recibir la renta de una capellanía fundada que les permitiera tener una congrua suficiente.

Ahora bien, quienes lo hacían a título de patrimonio debían justificar la posesión de bienes de los cuales pudieran obtener un sustento. Por último, el título de suficiencia era para aquellos que, por sus méritos, concebían que merecían el beneficio de ser ordenados (Lavallé, 2011).

Entre 1810 y 1821, un total de 632 individuos recibió 1636 órdenes sacerdotales, y se registró un promedio de 136.3 órdenes conferidas por año. El año 1812 no aparece registrado en las matrículas por razones que desconozco, aunque infiero que es debido a la ausencia del arzobispo Bergosa y Jordán que, como ya vimos, llegó a la ciudad de México hasta 1813 (Tabla 1). 
Tabla 1

Órdenes sacerdotales conferidas en el arzobispado de México, 1810-1821

\begin{tabular}{|c|c|c|c|c|c|c|}
\hline Año & Primera tonsura & Órdenes menores & Subdiácono & Diácono & Presbítero & Total \\
\hline 1810 & 21 & 22 & 19 & 38 & 31 & 131 \\
\hline 1811 & 13 & 14 & 14 & 5 & 10 & 56 \\
\hline 1812 & - & - & - & - & - & - \\
1813 & 45 & 36 & 30 & 28 & 38 & 177 \\
\hline 1814 & 61 & 66 & 56 & 58 & 49 & 290 \\
\hline 1815 & 40 & 41 & 48 & 46 & 49 & 224 \\
\hline 1816 & 48 & 34 & 27 & 28 & 28 & 165 \\
\hline 1817 & 23 & 22 & 23 & 34 & 33 & 135 \\
\hline 1818 & 35 & 27 & 22 & 21 & 28 & 133 \\
\hline 1819 & 27 & 25 & 21 & 20 & 20 & 113 \\
\hline 1820 & 26 & 26 & 27 & 29 & 25 & 133 \\
\hline 1821 & 21 & 14 & 11 & 15 & 18 & 79 \\
\hline Totales & $\mathbf{3 6 0}$ & $\mathbf{3 2 7}$ & $\mathbf{2 9 8}$ & $\mathbf{3 2 2}$ & $\mathbf{3 2 9}$ & $\mathbf{1 6 3 6}$ \\
\hline
\end{tabular}

Fuente: elaboración propia con base en AHAM, episcopal, secretaría arzobispal, libros de matrículas de órdenes, estantería, libro 10.

En la gráfica 1 puede observarse con mayor perspectiva la evolución numérica de las ordenaciones en el periodo estudiado. Tal como se advierte, al estallido de la insurgencia, entre los años 1810 y 1811 ocurrió un descenso del $57.2 \%$ del índice de ordenaciones con respecto al primer año, lo cual parece indicar que es derivado de la turbulencia política y del fallecimiento del arzobispo Lizana y Beaumont en 1811.

Para el año 1813, ya con el arzobispo electo Bergosa y Jordán al frente, las ordenaciones nuevamente incrementaron su número, superando los registros de 1810, y tocarían su punto más alto en 1814 con un total de 290. De allí y hasta 1821 la tendencia de las ordenaciones fue a la baja, sólo con muy breves y poco notorias recuperaciones en 1818 y 1821 . Entre las razones que explicarían este cambio en la tendencia se encuentran, por un lado, un menor interés y condiciones por parte de los prospectos a ingresar al clero y, por otro, la promoción de nuevos clérigos por parte del arzobispo Bergosa y Jordán y una mayor limitación a los aspirantes por parte de Pedro de Fonte. Será per- tinente que estudios posteriores ofrezcan mayor luz para explicar este cambio notorio con mayores elementos.

\section{Gráfica 1 \\ Ordenaciones sacerdotales conferidas en el arzobispado de México, 1810-1821}

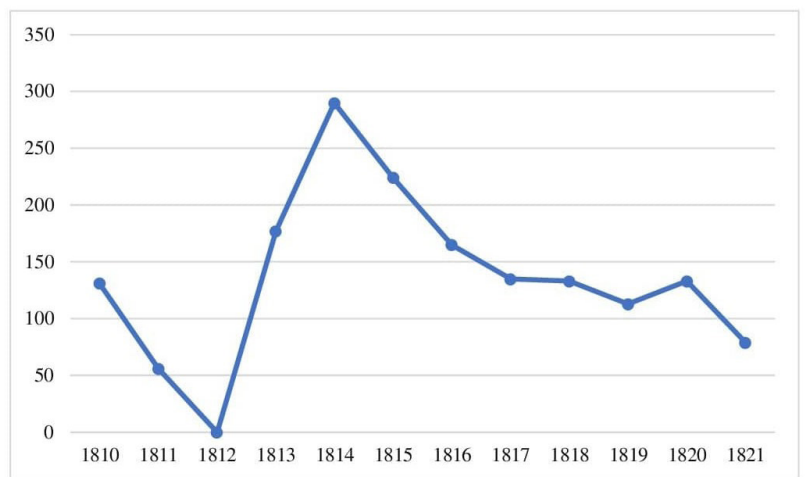

Fuente: elaboración propia con base en AHAM, episcopal, secretaría arzobispal, libros de matrículas de órdenes, estantería, libro 10. Nota: el año 1812 no aparece registrado en el libro de matrículas. 
Es interesante también advertir que en el periodo de sede vacante a la muerte de Lizana y Beaumont las ordenaciones sacerdotales no se incrementaron súbitamente, como fue común, por ejemplo, en la sede vacante que antecedió al arzobispo Lanciego y Eguilaz un siglo antes. ${ }^{10}$ No todos los ordenandos cubrieron cada una de las diferentes órdenes que podían recibir (como era lo esperado), pues varios de ellos -al menos en los 12 años aquí estudiados- ejercieron el ministerio sólo hasta el subdiaconado o el diaconado, por ejemplo. Lo ideal era que todos alcanzaran el orden del presbiterado, que era el que les permitía ejercer cabalmente el ministerio sacerdotal a través de la cura de almas y les facultaba para ser promovidos a una parroquia.

El $52 \%$ de los individuos que se ordenaron se convirtieron en presbíteros, lo que significa que al menos uno de cada dos ordenandos estaba disponible para ocupar una parroquia. El $61 \%$ de los presbíteros ordenados, es decir, más de la mitad, recibió su orden durante la gestión arzobispal de Pedro de Fonte. Lo anterior significa que un mayor número de ordenaciones no era correspondiente con un mayor número de presbíteros; esto explica por qué si en el gobierno del arzobispo Fonte disminuyeron las ordenaciones, la cantidad de presbíteros fue mayor en su prelatura. No obstante, las ordenaciones de presbíteros disminuyeron de acuerdo con la tendencia general (gráfica 2).

\section{Gráfica 2 \\ Ordenación de presbíteros en el arzobispado de México, 1810-1821}

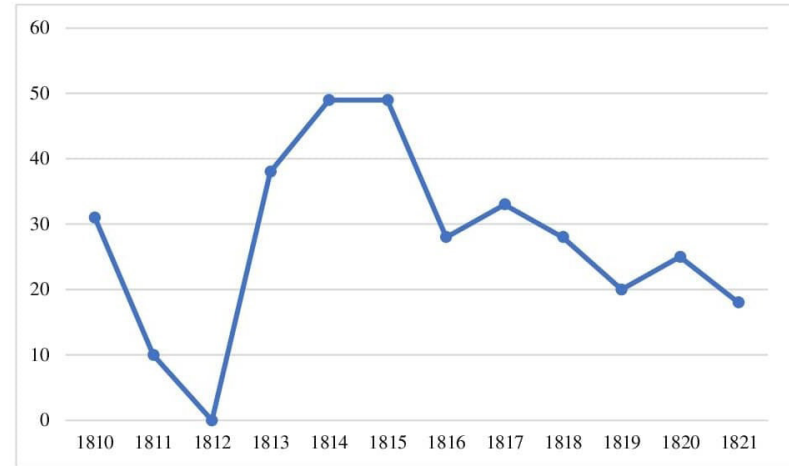

Fuente: elaboración propia con base en AHAM, episcopal, secretaría arzobispal, libros de matrículas de órdenes, estantería, libro 10. Nota: el año 1812 no aparece registrado en el libro de matrículas.

10 Para profundizar sobre este aspecto puede consultarse a Aguirre Salvador (2012).

Ahora bien, con respecto a los títulos de ordenación, en la tabla 2 pueden observarse las sumatorias por año y sus respectivos porcentajes; he preferido presentarlo de este modo porque por medio de los porcentajes resulta más claro establecer las proporciones de los títulos de ordenación, pues el número de órdenes conferidas entre un año y otro son variables.

Tabla 2

Títulos de ordenación en el arzobispado de México, 1810-1821

\begin{tabular}{|c|c|c|c|c|c|c|c|c|c|c|}
\hline Año & Capellanía & $\%$ & Lengua & $\%$ & Patrimonio & $\%$ & Suficiencia & $\%$ & No indica & $\%$ \\
\hline 1810 & 72 & 54.9 & 52 & 39.6 & 3 & 2.2 & O & 0 & 4 & 3 \\
\hline 1811 & 27 & 48.2 & 26 & 46.4 & 3 & 5.3 & 0 & 0 & 0 & 0 \\
\hline 1812 & - & - & - & - & - & - & - & - & - & - \\
\hline 1813 & 32 & 18 & 42 & 23.7 & 0 & 0 & 2 & 1.1 & 101 & 57 \\
\hline 1814 & 118 & 40.6 & 119 & 41 & 7 & 2.4 & 12 & 4.1 & 34 & 11.7 \\
\hline 1815 & 105 & 46.8 & 111 & 49.5 & 5 & 2.2 & 3 & 1.3 & $\mathrm{O}$ & 0 \\
\hline 1816 & 92 & 55.7 & 68 & 41.2 & 3 & 1.8 & 2 & 1.2 & O & 0 \\
\hline 1817 & 70 & 51.8 & 63 & 46.6 & 2 & 1.4 & O & 0 & $\mathrm{O}$ & 0 \\
\hline 1818 & 64 & 48.1 & 68 & 51.1 & $\mathrm{O}$ & 0 & 1 & 0.7 & $\mathrm{O}$ & 0 \\
\hline 1819 & 51 & 45.1 & 57 & 50.4 & 1 & 0.8 & 4 & 3.5 & 0 & 0 \\
\hline 1820 & 61 & 45.8 & 64 & 48.1 & 5 & 3.7 & 1 & 0.7 & 2 & 1.5 \\
\hline 1821 & 38 & 48.1 & 34 & 43 & 3 & 3.7 & 3 & 3.7 & 1 & 1.2 \\
\hline Totales & 730 & 44.6 & 704 & 43 & 32 & 1.9 & 28 & 1.7 & 142 & 8.6 \\
\hline
\end{tabular}

Fuente: elaboración propia con base en AHAM, episcopal, secretaría arzobispal, libros de matrículas de órdenes, estantería, libro 10. 
En la gráfica 3 se comparan los porcentajes de los títulos de ordenación del clero secular en el arzobispado de México. A primera vista se advierte que las ordenaciones a título de capellanía y a título de lengua fueron las más recurrentes. En los años 1810, 1816, 1817 y 1821 las ordenaciones a título de capellanía fueron mayores, mientras que en 1813, 1814, 1815, 1818, 1819 y 1820 se confirieron más órdenes por vía de lengua. Por desgracia existe, para 1813, un porcentaje muy marcado de ordenaciones en las cuales no fue señalado el título bajo el cual éstas se obtuvieron.

Según la misma gráfica, parece que los ordenandos fueron más consistentes para solicitar órdenes a título de lengua, aunque "capellanía" y "lengua" tuvieron un comportamiento semejante a lo largo del periodo. En los años 1810 y 1811, mientras que las ordenaciones a título de capellanía disminuyeron, las de título de lengua se incrementaron. Entre 1813 y 1815 -es decir, durante el gobierno de Bergosa y Jordán-, aunque ambos títulos fueron incrementando, las ordenaciones a título de lengua fueron superiores.

Gráfica 3

Porcentajes de títulos de ordenación en el arzobispado de México, 1810-1821

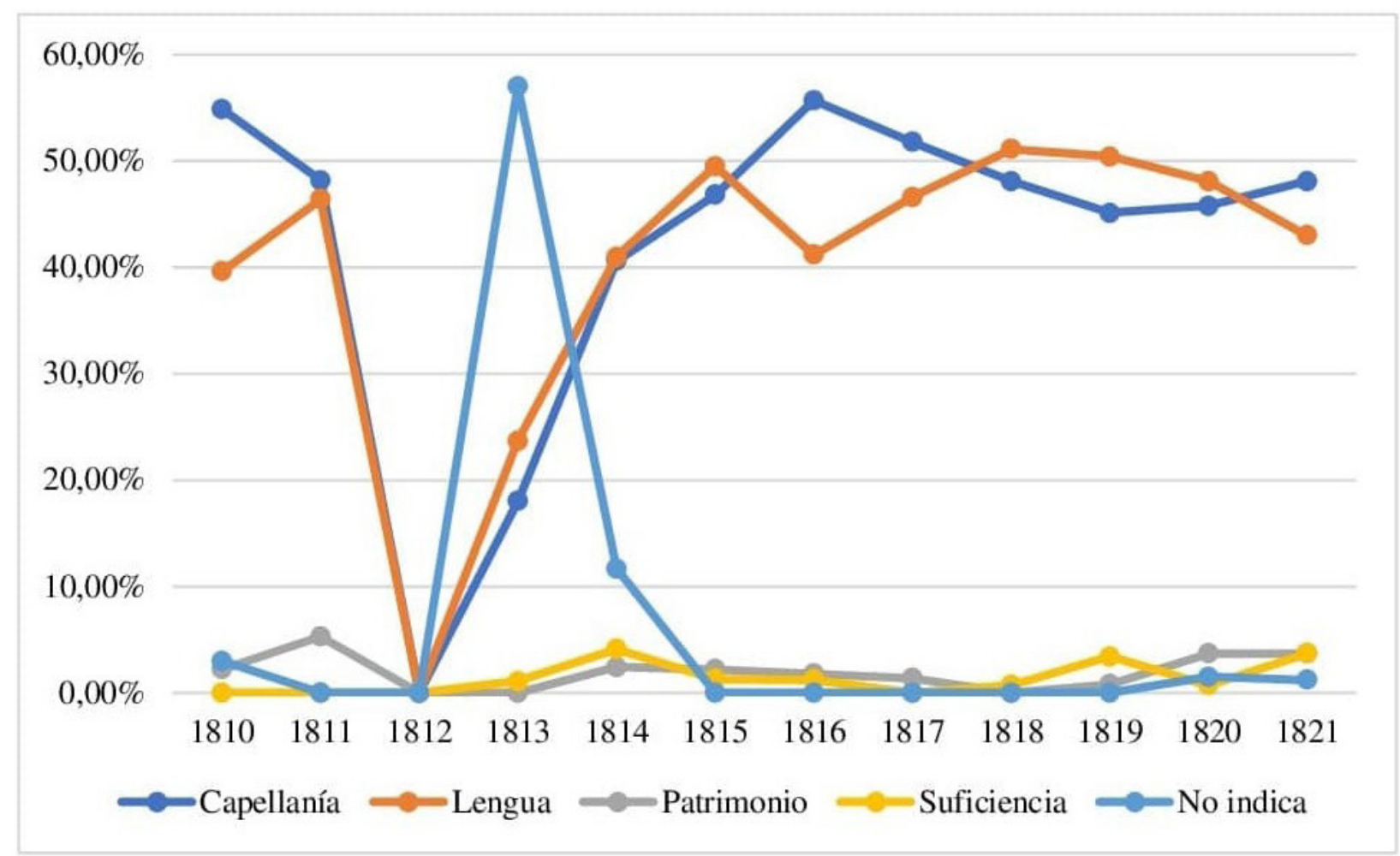

Fuente: elaboración propia con base en AHAM, episcopal, secretaría arzobispal, libros de matrículas de órdenes, estantería, libro 10.

Nota: el año 1812 no aparece registrado en el libro de matrículas.

Para 1816, las ordenaciones a título de capellanía eran superiores y lo mismo fue en 1817, mientras que las ordenaciones a título de lengua disminuyeron para, nuevamente, incrementar en 1817 y 1818, fecha última en que otra vez se posicionaron como la primera vía de acceso al sacerdocio. Este aumento coincidió con el ligero incremento que registraron las órdenes conferidas en 1818 y 1820. En el último año aquí estudiado, las capellanías retomaron su tendencia al alza, mientras que la lengua lo hizo a la baja. 
Aunque también es cierto que el número de órdenes disminuyó en comparación con la primera mitad del siglo XVIII -que es el periodo hasta ahora estudiado por Aguirre Salvador (2012)- esto pudo deberse a varios factores. Por un lado, la situación bélica de la Nueva España que obligaba a los individuos a resolver con mayor premura sus necesidades más apremiantes antes que pretender alistarse a las filas del clero, las limitaciones para contar con una capellanía bajo la cual ordenarse y las dificultades de los prelados para conferir órdenes a los aspirantes al sacerdocio por el interés que les requería la situación política novohispana.

El resto de los títulos de ordenación no presentó mayor notoriedad en el periodo estudiado. Es interesante mirar el comportamiento de las ordenaciones por capellanía y por lengua, cuyos porcentajes son de $44.6 \%$ y $43 \%$, respectivamente; es decir, no existe una diferencia muy marcada entre ambos.

Como ha quedado evidente, las ordenaciones a título de lengua continuaban siendo un importante vehículo de ingreso al clero. Esto demuestra que, al menos en este rubro, la política castellanizadora que desde el siglo XVIII se implementaba con mayor fuerza seguía sin dar los resultados deseados. De hecho, todavía durante la prelatura del primer arzobispo del México independiente, Manuel Posada y Garduño, las ordenaciones a título de lengua eran una vía para ingresar al estado eclesiástico (Bravo Rubio, 2013). En la tabla 3 puede observarse la variedad de lenguas que los aspirantes registraron al momento de pretender su ordenación. El $62.6 \%$ de las órdenes a título de lengua fue en náhuatl o mexicano, casi el doble de la lengua otomí, que apenas alcanzó $31.1 \%$.

\section{Tabla 3 \\ Lenguas presentadas como título de ordenación sacerdotal en el arzobispado de México, 1810-1821}

\begin{tabular}{|c|c|c|c|c|c|c|c|c|c|c|c|}
\hline Año & Mexicano & Otomí & Mazahua & Zapoteco & Chinanteco & Chocho & Mixe & Mixteco & Tlapaneco & Totonaco & Huasteco \\
\hline 1810 & 36 & 16 & - & - & - & - & - & - & - & - & - \\
\hline 1811 & 19 & 7 & - & - & - & - & - & - & - & - & - \\
\hline 1812 & - & - & - & - & - & - & - & - & - & - & - \\
\hline 1813 & 31 & 7 & 4 & - & - & - & - & - & - & - & - \\
\hline $1814^{*}$ & 64 & 34 & 2 & 7 & 1 & 1 & 1 & 2 & 3 & 3 & - \\
\hline 1815 & 66 & 36 & - & 1 & - & - & - & 1 & - & 5 & 2 \\
\hline 1816 & 35 & 28 & 4 & - & - & - & - & - & - & - & 1 \\
\hline 1817 & 40 & 22 & - & - & - & - & - & - & - & - & 1 \\
\hline 1818 & 44 & 22 & - & - & - & - & - & - & - & - & 2 \\
\hline 1819 & 29 & 26 & - & - & - & - & - & - & - & - & 2 \\
\hline 1820 & 48 & 16 & - & - & - & - & - & - & - & - & - \\
\hline 1821 & 29 & 5 & - & - & - & - & - & - & - & - & - \\
\hline Totales & 441 & 219 & 10 & 8 & 1 & 1 & 1 & 3 & 3 & 8 & 8 \\
\hline
\end{tabular}

* El secretario no registró la lengua en que fue ordenado un individuo.

Fuente: elaboración propia con base en AHAM, episcopal, secretaría arzobispal, libros de matrículas de órdenes, estantería, libro 10.

La mayoría de las demás lenguas registradas en las matrículas no corresponde precisamente a las habladas dentro de la jurisdicción arzobispal. Algunas como el zapoteco, el mixe o el mixteco procedían del obispado de Antequera. De hecho, los años en que la diversidad de lenguas aumentó fue durante la gestión del obispo de aquella diócesis, Antonio Bergosa y Jordán. 
Esto me permite analizar un último aspecto de las ordenaciones en este periodo, y me refiero a quienes procedían de otra diócesis y acudían a la ciudad de México a ordenarse. En los libros de matrículas no viene especificado, al menos para estos años, si el aspirante a órdenes decidió quedarse en la jurisdicción arzobispal, pues habrá que recordar que, según los decretos conciliares, el ordenando estaba obligado a permanecer en el nuevo obispado. Del total de órdenes otorgadas, al menos 154 correspondieron a sujetos procedentes de otras regiones, y solamente 29 procedían de obispados ubicados en la península, tal como se observa en la tabla 4.

Tabla 4

\section{Órdenes conferidas a ordenandos procedentes de otros obispados y ordenados en el arzobispado de México, 1810-1821}

\begin{tabular}{|c|c|c|c|c|c|c|c|}
\hline Año & Michoacán & Guadalajara & Puebla & Antequera & Pamplona & Calahorra & Monterrey \\
\hline 1810 & - & 1 & 1 & - & - & - & - \\
\hline 1811 & - & - & - & - & - & - & - \\
\hline 1812 & - & - & - & - & - & - & - \\
\hline 1813 & 4 & - & - & - & - & - & - \\
\hline 1814 & 13 & - & 55 & 15 & - & - & 1 \\
\hline 1815 & 2 & - & 19 & 4 & - & - & 1 \\
\hline 1816 & 2 & - & - & - & 22 & 1 & - \\
\hline 1817 & 1 & - & - & - & 4 & 2 & - \\
\hline 1818 & 1 & - & 1 & - & - & - & - \\
\hline 1819 & 2 & - & - & - & - & - & - \\
\hline 1820 & 1 & - & 1 & - & - & - & - \\
\hline 1821 & - & - & - & - & - & - & - \\
\hline Totales & 26 & 1 & 77 & 19 & 26 & 3 & 2 \\
\hline
\end{tabular}

Fuente: elaboración propia con base en AHAM, episcopal, secretaría arzobispal, libros de matrículas de órdenes, estantería, libro 10.

Como sabemos por algunos estudios (Hernández González, 1990), la emigración de clérigos de España a América en búsqueda de una mayor estabilidad económica no era una novedad. Con la información que ofrecen las matrículas no es posible determinar las causas por las que los clérigos se ordenaron en una diócesis al otro lado del Atlántico, aunque éstas pueden ser, como sugiere Carbajal López (2015), derivado de una misión institucional o como escape por haber transgredido normas propias de su estado eclesiástico efectuadas en sus obispados de origen. No siempre sucedía que fueran clérigos huidizos, algunas otras veces se trataba de ordenandos que tenían algunos años residiendo en Nueva España y, por su estancia en América, buscaban su ordenación en el arzobispado de México o en cualquier otra diócesis indiana.

El $50 \%$ de las ordenaciones fue conferido a ordenandos avecindados en el obispado de Puebla, siguiéndole Michoacán y Pamplona con $20.9 \%$ cada uno, y Antequera con $12.3 \%$. Durante la gestión del arzobispo Antonio Bergosa y Jordán el número de ordenaciones a sujetos que presentaron dimisorias fue de 114, lo que corresponde al $74 \%$ del total de sujetos originarios de otros obispados. Esto significa que el aumento de la clerecía durante la prelatura de este mitrado recibió un impulso de individuos provenientes de otras diócesis. 


\section{Reflexiones finales}

La formación del clero secular en las diócesis de la provincia eclesiástica de México durante el periodo novohispano es un asunto aún no resuelto. Hasta ahora es difícil establecer comparaciones entre los diferentes obispados que no se restrinjan a estimaciones muy generales derivadas de informes -no pocas veces- tendenciosos de las autoridades eclesiásticas y civiles de la época. Al menos, por las reacciones de los mitrados, podemos tener un indicio de que el clero de cada región, no obstante, fuera secular o regular, presentó características muy particulares durante los años aquí estudiados que ameritan estudios posteriores más profundos.

A través de la opinión de los arzobispos es posible conocer las diferencias de percepción que tenían los mitrados sobre su clero, por ejemplo, los de México con respecto a los de Michoacán, al momento de la insurgencia. Mientras que en este último obispado la reacción fue más agresiva contra su clerecía por haber estallado allí el movimiento armado, en el arzobispado, el prelado Francisco Xavier de Lizana y Beaumont mostró una actitud más ecuánime, pero no por ello menos indiferente a la participación del clero en la diócesis vecina.

Lo anterior dio pie para analizar si las percepciones de los arzobispos sobre su clero influyeron en la formación de nuevos clérigos entre los años 1810 y 1821. Las tendencias de ordenación indican que los factores son diversos, pero grosso modo la participación de curas en la revolución armada no parece haber influido en una disminución de nuevos ordenados, al menos no desde la óptica de los arzobispos. El argumento de esta idea es que los clérigos del arzobispado, aunque afectados por las reformas político-administrativas de finales del siglo XVIII, no pretendían vengar las limitaciones que la Corona les había impuesto simplemente porque su influencia en la vida local y regional, en gran medida, siguió sin mayores cambios. De hecho, una razón por la cual los prelados siguieron confiando en los clérigos fue porque conservaban el poder de convocatoria que la Corona les quiso restringir.

Esta situación habría influido para que el arzobispado no viera en su ejército de clérigos un enemigo a vencer sino un aliado a la causa realista, pero ¿cómo los clérigos podían ser útiles? Para el arzobispo Bergosa y Jordán la postura de la clerecía debía ser con una presencia más activa en la lucha armada, mientras que para el mitrado Fonte los sacerdotes podían brindar un apoyo más eficaz refrendando su lealtad a la Corona y concentrándose mayormente en sus tareas pastorales.

La disminución en las ordenaciones sacerdotales al acercarse la insurgencia derivó de una tendencia que se gestó desde mediados de la primera década del siglo XIX. Esta disminución continuó su curso tras el nombramiento del arzobispo Lizana como virrey de Nueva España entre 1809 y 1810, y su fallecimiento en 1811. La ausencia de ordenaciones en 1812 correspondería a la también ausencia del arzobispo electo Antonio Bergosa y Jordán, quien no llegó a la ciudad de México sino hasta 1813.

Con Bergosa y Jordán las ordenaciones aumentaron, es posible que por la percepción que tuvo de los clérigos como agentes activos en la contrainsurgencia, pero al final de su gestión nuevamente disminuyeron. ¿Será posible que los aspirantes a órdenes provenientes del obispado de Antequera vieran mayores oportunidades de acceder al sacerdocio si se ordenaban en la Ciudad de México? Esta tendencia a la baja fue continuada por su sucesor, el arzobispo Pedro de Fonte. Desde mi punto de vista, es difícil afirmar que Fonte limitara las ordenaciones por temor a que su clero se rebelara pues, como vimos, el mayor número de presbíteros se ordenaron durante su administración.

En términos generales, las órdenes sacerdotales otorgadas durante la guerra de independencia en el arzobispado de México decrecieron. El periodo insurgente y los primeros años del México independiente requieren todavía estudios más diversos que escapen de aquellos lugares comunes. Por ejemplo, un aspecto que convendría que 
trabajos futuros atiendan es el análisis de la población clerical y sus destinos, pues si en este texto presenté las tendencias numéricas de las ordenaciones, es pertinente también conocer en qué se ocupó el clero ordenado durante los años 1810-1821.

¿Por qué disminuyeron las ordenaciones sacerdotales en tiempos de la insurgencia mexicana? Es posible que los aspirantes vieran entorpecidas sus intenciones, no porque el estado eclesiástico dejase de ser atractivo por los beneficios que otorgaba, sino porque la situación, políticamente inestable, no ofrecía las condiciones para ordenarse por razones tan diversas como las dificultades para trasladarse a la capital, realizar su postulación y ser examinados, o las circunstancias económicas que imposibilitaban la fundación de nuevas capellanías. Aunado a lo anterior, las ausencias de los arzobispos, sus labores políticas cuando fungían como virreyes (como el caso de Lizana y Beaumont), la poca seguridad para mantenerse en el cargo (como Bergosa y Jordán) y la pastoral puesta en marcha (como sucedió con Fonte) también pudieron obstaculizar la formación de ministros eclesiásticos. Para bien o para mal, la insurgencia sí disminuyó la tendencia en la ordenación de nuevos clérigos; en qué medida este descenso afectó las principales funciones de la Iglesia en los años posteriores es una materia pendiente aún por resolver.

\section{Fuentes consultadas}

\section{Documentos de archivo}

Archivo Histórico del Arzobispado de México (AHAM)

Episcopal, secretaría arzobispal, libros de matrículas de órdenes, estantería, libro 10.

Episcopal, secretaría arzobispal, cabildo sede vacante, caja 162, expediente 16 , folios 4 y 23.

Episcopal, secretaría arzobispal, cartas pastorales, caja 166, expediente 44, folio 4.

Episcopal, secretaría arzobispal, cartas pastorales, caja 166, expediente 44, folio 5.

Episcopal, secretaría arzobispal, cartas pastorales, caja 166, expediente 44, folios 8-9

\section{Referencias}

Aguirre Salvador, Rodolfo (2016), "Actitudes y críticas de los curas ante las reformas parroquiales en el arzobispado de México, 1749-1776", en Pilar Martínez López-Cano y Francisco Javier Cervantes Bello (coords.), La dimensión imperial de la Iglesia novohispana, Ciudad de México, Universidad Nacional Autónoma de México/ Benemérita Universidad Autónoma de Puebla, pp. 330-356.

Aguirre Salvador, Rodolfo (2012), Un clero en transición. Población clerical, cambio parroquial y política eclesiástica en el arzobispado de México, 1700-1749, Ciudad de México, Universidad Nacional Autónoma de México.

Aguirre Salvador, Rodolfo (2011), "Sobrevivir a la insurgencia: Ios curas y la conservación de las parroquias. Arzobispado de México, 1813-1820", en Francisco Javier Cervantes Bello, Lucrecia Enríquez y Rodolfo Aguirre Salvador (coords.), Tradición y reforma en la Iglesia hispanoamericana, 1750-1840, Ciudad de México, Universidad Nacional Autónoma de México/ Benemérita Universidad Autónoma de Puebla, pp. 167-195. 
Aguirre Salvador, Rodolfo (2010), "Ambigüedades convenientes. Los curas del arzobispado de México frente al conflicto insurgente", en Brian Connaughton (coord.), Religión, política e identidad en la independencia de México, Ciudad de México, Universidad Autónoma Metropolitana, pp. 273-305.

Aguirre Salvador, Rodolfo (2009), "El clero secular del arzobispado de México: oficios y ocupaciones en la primera mitad del siglo XVIII", Letras Históricas, (1), Guadalajara, Universidad de Guadalajara, pp. 67-93.

Brading, David Anthony (1981), "El clero mexicano y el movimiento insurgente de 1810", Relaciones. Estudios de Historia y Sociedad, 2 (5), Zamora, El Colegio de Michoacán, pp. 5-26.

Bravo Rubio, Berenise (2013), La gestión episcopal de Manuel Posada y Garduño. República católica y arzobispado de México, 1840-1846, Ciudad de México, Porrúa Print.

Bravo Rubio, Berenise y Pérez Iturbe, Marco Antonio (2001), "Una Iglesia en busca de su independencia: el clero secular del arzobispado de México, 1803-1822", tesis colectiva de licenciatura, Universidad Nacional Autónoma de México, Ciudad de México.

Carbajal López, David (2015), "Personas sagradas y trayectorias trasatlánticas: la vida de tres clérigos de principios del siglo XIX en Nueva España", Letras Históricas, (11), Guadalajara, Universidad de Guadalajara, pp. 79-101.

Castillo Flores, José Gabino (2018), "Francisco Xavier de Lizana y Beaumont: arzobispo de México y Virrey de la Nueva España (1802-1811)", en Marta Eugenia García Ugarte (coord.), Ilustración católica. Ministerio episcopal y episcopado en México, 1758-1829, Tomo I. Región centro, Ciudad de México, Universidad Nacional Autónoma de México, pp. 200-238.
Escrig Rosa, Josep (2021), "La Guerra de la Independencia de México como guerra religiosa: la mirada antiinsurgente y contrarrevolucionaria ante los sucesos de 1810 y 1821", Anuario de Estudios Americanos, 78 (1), Sevilla, Escuela de Estudios Hispano-Americanos, pp. 223-255.

Farris, Nancy (1995), La Corona y el clero en el México colonial, 1579-1821. La crisis del privilegio eclesiástico, Ciudad de México, Fondo de Cultura Económica.

Fonte, Pedro Josef de (1996), "Informe muy reservado sobre el estado político y social de la Nueva España, 1809", en David Brading, El ocaso novohispano: testimonios documentales (trad. Antonio Saborit), Ciudad de México, Instituto Nacional de Antropología e Historia/ Consejo Nacional para la Cultura y las Artes, pp. 277-318.

Fonte, Pedro Josef de (1816), Don Pedro Josef de Fonte, por la gracia de Dios y de la Santa Sede Apostólica arzobispo de México, del Consejo de Su Majestad, etcétera, a todos mis amados diocesanos, Ciudad de México, Alejandro Valdés., pp. 6-75, <https://acortar.link/tztIRd>, 31 de mayo de 2021.

Fonte, Pedro Josef de (1815), Circular del llustrísimo Señor Arzobispo electo y gobernador de esta diócesis a los curas y ministros de las parroquias de ella, Ciudad de México, s.e., <https://acortar.link/4pyZKZ>, 31 de mayo de 2021.

García, Genaro (1906), Documentos inéditos o muy raros para la historia de México. Tomo IX. El clero de México y la guerra de independencia. Documentos del arzobispado de México, Ciudad de México, Librería de Vda. De Ch. Bouret.

Hamnett, Brian R. (2009), "Antonio Bergosa y Jordán (1748-1819), obispo de México: ¿ilustrado? ¿reaccionario? ¿contemporizador y oportunista?", Historia Mexicana, 59 (1) (233), Ciudad de México, El Colegio de México, pp. 117-136. 
Hernández González, Manuel (1990), "La emigración del clero secular canario a América en el último cuarto del siglo XVIII", Anuario del Archivo Histórico Insular de Fuerteventura, (3), Fuerteventura, Cabildo Insular de Fuerteventura, pp. 13-24.

Hernández Jaimes, Jesús (2017), "La insurgencia en el sur de la Nueva España, 1808-1814. ¿̇lnsurrección del clero?", en Ana Carolina Ibarra (coord.), La independencia en el sur de México, Ciudad de México, Universidad Nacional Autónoma de México/ Fideicomiso Felipe Teixidor y Monserrat Alfau de Teixidor, pp. 61-104.

Ibarra, Ana Carolina (2010), El clero de la Nueva España durante el proceso de independencia, 1808-1821, Ciudad de México, Universidad Nacional Autónoma de México.

Ibarra, Ana Carolina (2000), El cabildo catedral de Antequera, Oaxaca y el movimiento insurgente, Zamora, El Colegio de Michoacán.

Ibarra González, Ana Carolina y Quezada Lara, José Luis (2018), "Antonio Bergosa y Jordán. Obispo de Antequera (Oaxaca) y obispo electo de México (17481819)", en Marta Eugenia García Ugarte (coord.), Ilustración católica. Ministerio episcopal y episcopado en México, 1758-1829. Tomo II. Región occidente, sur y norte, Ciudad de México, Universidad Nacional Autónoma de México, pp. 132-165.

Irigoyen López, Antonio (2016) "Sobre el ingreso en el clero: a cuestas con la vocación y con las estrategias familiares en la España del siglo XVIII", Revista de Historia Social y de las Mentalidades, 20 (2), Santiago, Universidad de Santiago de Chile, pp. 101-131.

Lavallé, Bernard (2011), "Hacia un nuevo clero en los Andes a finales del siglo XVIII: la ordenación A título de lengua en el Arzobispado de Lima", Revista de Indias, 71 (252), Madrid, Centro de Ciencias Humanas y Sociales, pp. 391-414.
Lavallé, Bernard (2005), "Miedo reverencial versus justo miedo: presiones familiares y vocación religiosa en Lima (16501700)", en Claudia Rosas Lauro (ed.), El miedo en el Perú. Siglos XVI al XX, Lima, Pontificia Universidad Católica del Perú, pp. 83-102.

Lizana y Beaumont, Francisco Xavier de (1803), Carta pastoral que el llustrísimo Señor Don Francisco Xavier de Lizana y Beaumont dirige a sus eclesiásticos sobre la dignidad y grandeza del Estado Sacerdotal y sus obligaciones, Ciudad de México, Imprenta Madrileña de la Calle de Santo Domingo y Esquina de Tacuba.

Lynch, John (2001), América Latina, entre colonia y nación, Barcelona, Crítica.

Martínez Albesa, Emilio (2018), "El arzobispo Pedro José de Fonte y su renuncia. Legitimismo, ilustración, celo pastoral y libertad de conciencia (1815-1837)", en Marta Eugenia García Ugarte (coord.), llustración católica. Ministerio episcopal y episcopado en México, 1758-1829. Tomo I. Región centro, Ciudad de México, Universidad Nacional Autónoma de México, pp. 239-307.

Murillo Velarde, Pedro (2004), Curso de derecho canónico hispano e indiano, Zamora, El Colegio de Michoacán/ Universidad Nacional Autónoma de México.

Pérez Puente, Leticia; González González, Enrique y Aguirre Salvador, Rodolfo (2004), "Concilio III Provincial Mexicano celebrado en México el año 1585. Aprobación del concilio confirmación del sínodo provincial de México Sixto $\checkmark$, Papa para futura memoria", en María del Pilar Martínez López-Cano (coord.), Concilios Provinciales Mexicanos. Época colonial, Ciudad de México, Universidad Nacional Autónoma de México, pp. 1-360.

Taylor, William B. (1999), Ministros de lo sagrado. Sacerdotes y feligreses en el México del siglo XVIII, Zamora, El Colegio de Michoacán/ Secretaría de Gobernación/ El Colegio de México. 
Taylor, William B. (1995), "El camino de los curas y de los Borbones hacia la modernidad", en Álvaro Matute, Evelia Trejo, Brian Connaughton (coords.), Estado, Iglesia y sociedad en México, siglo XIX, Ciudad de México, Universidad Nacional Autónoma de México/ Miguel Ángel Porrúa, pp. 81-113.

Van Young, Eric (2006), La otra rebelión. La lucha por la independencia de México, 1810-1821, Ciudad de México, Fondo de Cultura Económica.

Van Young, Eric (1992), La crisis del orden colonial. Estructura agraria y rebeliones populares de la Nueva España, 17501821, Ciudad de México, Alianza Editorial.

Vivero Domínguez, Luis Fernando (2019), "El clero de la Provincia de la Plata: dinámica parroquial y conflicto social en Sultepec, Temascaltepec y Zacualpan en el siglo XVIII", tesis de licenciatura, Universidad Autónoma del Estado de México, Toluca.

Vizuete Mendoza, Carlos (2004), "La situación económica del clero novohispano en la segunda mitad del siglo XVIII", Análisis económico, 18 (42), México, Universidad Autónoma Metropolitana, pp. 319-343.

Von Wobeser, Gisela (2006), "La consolidación de vales reales como factor determinante de la lucha de independencia en México, 1804-1808", Historia Mexicana, 56 (2), Ciudad de México, El Colegio de México, pp. 373-425.

Recibido: 10 de junio de 2021. Reenviado: 18 de junio de 2021. Aceptado: 1 de agosto de 2021.

\section{Luis Fernando Vivero Domínguez}

Es licenciado en Historia por la Universidad Autónoma del Estado de México. Actualmente es alumno de la Maestría en Historia en la Universidad Nacional Autónoma de México, donde realiza una investigación sobre la evolución y tendencias ocupacionales de la población clerical en el arzobispado de México durante la segunda mitad del siglo XVIII. Obtuvo el Premio Nacional "Francisco Javier Clavijero" a Mejor Tesis de Licenciatura en Historia y Etnohistoria, otorgado por el Instituto Nacional de Antropología e Historia, en 2020, por la tesis "El clero de la Provincia de la Plata: dinámica parroquial y conflicto social en Sultepec, Temascaltepec y Zacualpan en el siglo XVIII"; asimismo, con esta misma tesis, fue reconocido con una Mención Honorífica en el marco del Premio Nacional "Luis González y González", otorgada por El Colegio de Michoacán en el mismo año. 